joint in the great toe should be drawn to the ground by the strong flexor tendon attached to the final phalanx close to it; if another joint existed it must rise up, as occurs in the other toes, and the solid bearing would be lost. Apart from this, it must be admitted that it is mainly due to the special development of the great-toe in a line with the long axis of the foot that man is enabled to exercise the attribute, in all ages regarded as a noble one, of standing erect. Yet this special feature is the one which the conventional boot does most to conceal, and in direct proportion as it is successfully concealed the wearer is supposed to be dressed in good taste. It would seem to be regarded as necessary to reduce the foot to even-sided symmetry; but there is no law of beauty which requires this. Mr. Ruskin assuredly would not say that it is in any of " the eternal canons of loveliness" decreed that an object to be beautiful must be symmetrical. An architect required to provide more space on one than on the other side of a building would not seek to conceal or even to minimise the difference; he would seek rather to accentuate it, and give the two sides of the structure distinctive features. To me it appears that it is on this principle only that a boot, to be at once useful, graceful, and appropriate, can be designed.

Moreover, the sense of symmetry, natural and reasonable where the same function has to be performed, is, or ought to be, satisfied by the exact correspondence of the two feet, which, taken jointly, may be described as the two halves of an unequally expanded dome, irregularly extended at the base, the greatest extension being in the line of the greatest expansion of the dome, through which line the division runs. The dividing line thus makes the margin of the two feet parallel to each other. It may be that the inner margin of the great toe, if produced backwards, would fall a little distance from the inner side of the heel. A perfect adult foot, in which the great toe is not and never has been diverted outwards, and in which there has been no consequent thickening of the large joint, is not easy to find. In children the inner line is often visibly concave. It may be remarked that in rest the great toe is everted as well as drawn upwards, in which position the toes are usually packed in a tight, medium-pointed boot; it is only therefore in action as the toes are pressed against the ground that the full extent of the approximation to a straight inner line is seen.

In the boot it is of first importance that the sole (technicaliy, the part in front of the hollow or "waist") should allow the great toe to occupy its natural position ; it must, therefore, be straight or nearly so on the inner margin; but it is of little use to provide the room thus given unless it be occupied : the foot must be invited to occupy it by giving plenty of room in the upper leather on this side. It is obvious that where a flexible material is fixed on both sides and left loose between, it can be drawn furthest from the surface to which it is attached, in a line mid-way between the fixed parts. For this reason the highest part of the foot, which is on the inner side, will, in any case, have some tendency to go to the middle line of the boot where most room can be made; this tendency is largely and needlessly aggravated by the high ridge of the last being along the middle line instead of being on the inner margin. But not only ought the room there given to be much more according as the foot projects the more upwards ; it ought to be proportionally more. I have insisted that the foot does not lengthen in walking, but rather shortens. This shortening, due to the powerful action of the long flexors, causes the foot to rise across the middle, the rising being almost entirely on the inner side. Here, therefore, over (not by the side of) the ball of the great toe is special room required. The lateral thrust, too, already spoken of as consequent on turning out the toes, tends much to displace the foot and to throw it against the outside of the boot. Toe-caps also are objectionable, as giving the most room in the middle line and inviting the great toe to occupy that position.

No useful or ornamental purpose is served by leaving space unoccupied round the outer margin of the sole opposite the little toes, as if it were necessary to make the two sides of the boot to match. No angle existing in nature, none should be represented; the outline of the sole of the boot should conform to that of the foot.

If it be true, as already stated, that grace in walking, as well as free propulsion of the body onwards, and main tenance of the arch in walking, are all $d u e$ to the free action of the flexor muscles, letting the heel down with gentleness and precision, and raising it with firmness and vigour, it ollows that none of these can be if the boot prevent the heel from going down, a necessary antecedent to springing up. A low heel, therefore, if any, is imperative. The perfect boot should have none. Nor can the free action of the flexor muscles have full effect, so as to draw the toes to the ground. if the sole be turned up at the toes, especially if it be a stiff one. Some turning up will come from walking, however good, but there is no reason why it should be aggravated by having the boot-last so. In it the sole should be flat to the end.

Objection is made that boots with a straight, or nearly straight, inside line give the feet a pigeon-toed or inverted appearance, which is unnatural. This is not altogether due to the eye being accustomed to a more conventional pattern. It is, I am sure, mainly due to a removable cause. Any conspicuous line, that of the laces or a seam, is always carried from the front of the leg to a central point on the upper surface of the foot. The eye, falling on this line, in imagination continues or produces it, and so divides the front part diagonally into two very unequal portions, the larger on the inner side. I have found that if the line of the laces or seam be kept parallel throughont to the line of the long extensor tendon-in other words, along the crest of the ridge, thus narking out a distinctive feature,-the unpleasant effect is removed.

In proper walking, which cannot be done in an improper boot, friction of the foot on the sole and of the latter on the ground is reduced to a minimum, the sole being pressed against, not rubbed along, the surface. This is shown by the very little wearing of the leather; when at last it does give way, it should"be at an oval spot a little distance from the margin of the sole, under the middle joint of the great toew This is the last point to leave the ground in walking; here, therefore, is the greatest tendency to slide on the surface and: consequent friction.

The great toe, in any but the most perfect feet now to be. found, is so easily diverted outwards that socks and stockings with a straight inner line are very desirable, indeed, no others can be said to really fit the feet. When any consider able distortion exists, a separate stall for the great toe is necessary.

For the reasons given, a last should have the inner margin: nearly in a line with the inner side of the heel, and joining: in front by a rounded angle a long curve on the outer margin. where no angle should be shown. The sole should be flat, touching the base line in front. The thickest part (aighest vertically) should throughout be on the inner margin, especially above the ball of the great toe. The boots should have low heels-to be perfect none. 'I'he line of laces or of any conspicuous seam down the front should be in a line corresponding with the inner margin of the foot along the highest part. The boot should if possible be left on the last for a considerable time, to overcome the tendency of the leather to recoil after the forcible stretching to which it bas, been subjected, and so to fix it in its proper shape.

Some boots, and the lasts on which they were made, are shown in the Health Exhibition which will serve to illnstrate the latter part of this paper. They are exhibited by the maker, Mr. Henry Bletchly, of this city, who has taken very great pains to understand $m y$ wishes, and to use his own thorough knowledge of the technical operations involved as a means of overcoming difficulties in earrying them out. I have every reason to be satisfied with the result. His case (No, 260, Class 13) I would commend to the attention of those interested.

Gloucester.

\section{SCIATICA AND ITS ALLIES, AND THEIR TREATMENT BY THE BATH} \section{THERMAL WATERS. ${ }^{1}$}

BY JOHN KENT SPENDER, M.D. LOND., PHYSICIAN TO THE MINERAL WATER HOSPITAL, BATH.

SCrATICA is the generic name given to $\approx$ dyeæsthetic condition of the nervous apparatus of the lower limbs. The term is not meant to declare, by a process of exclusion, that only one nerve is affected, or that only one nerve mediates all the pain. Rather, it must be taken to connote the pain which is diffused over a certain nerve territory: now here, now there; sometimes condensed, so to speak, within a

Read before the Bath and Bristol Branch of the British Medical Association, A pril 17th, 1884 
small segment of nerve tubules; at other times spreading widely through the obvious relationships of contiguity and sympathy. Sciatica is a complex piece of pathology, because the sciatic nerve is complex in its anatomy and physiology. It is not a single nerve going straight from a nerve centre, and breaking up as it goes into motor and sensory branches; such "sweet simplicity" is not often nature's way, however much it might help our work as medical men. We have to deal with a great nerve, which is compound in its origin, which contains separate bundles of tubules having different functions, and which ultimately ramifies throughout the posterior, inferior, and outer parts of the lower extremity. When we add to this the inosculations with other nerves, and the anatomical relations of the sciatic trunk with the principal muscles, we have sufficient reasons why the medical problem before us often requires mature experience and special analytic skill.

Now, let us study briefly the origin and course of the sciatic nerve and its main subdivisions. It is formed principally by the fifth lumbar and first three sacral nerves; these combine into what is called a plexus, and from this issue two nerves of very different size and distribution, the great and small sciatic. Contributing to the plexus from above is the lumbo-sacral cord from the fourth lumbar nerve, and inferiorly it is joined by a communication from the fourth sacral, which goes to form the pudic nerve. For some distance the great sciatic nerve runs down the back of the thigh, with only a few muscular branches springing from it; but opposite the knee-joint it breaks up into its two large final divisions- $(\alpha)$ the internal popliteal, which goes to the inner and posterior parts of the leg and supplies most of the foot; and $(b)$ the external popliteal or peroneal, which is distributed to the outer side of the leg and to the dorsal surface of the foot and toes.

It is clear from this sketch that the sciatic nerve stands out in strong individuality - a magazine of nerve-force, so to speak, which is almost ganglionic in its sensorial acuteness and motorial energies. There is no analogue to it in the upper limbs ; here the big nerves split up into smaller threads, as if the delicate endowments of the forearm and hand ask for more specialised nerve conductors; and the physiological key of the matter seems to lie in the massive function of the lower limbs-their office in supporting the body and in performing locomotive acts. Again, the comparatively superficial course of such a large nerve is very noteworthy, and exposes a certain section of it to bending and outward pressure, to say nothing of traumatic accidents. Then, further, the track of the nerve makes it liable to be dragged and squeezed by tive action of the large muscles of the thigh, some of those very muscles which derive their motor supply from the nerve itself. These salient points in the anatomical mechanism of the sciatic nerve must modify its physiological properties and its pathological phenomena. We should expect pain to be a frequent symptom, weakness to be scarcely less common, and trophic changes to be by no means rare. Clinical experience teaches us that these morbid conditions exist in ever-varying degrees. In the vast majority of cases sciatica must be taken to signify pain or weakness, sometimes pain with weakness; one generally precedes the ocher, and one generally dominates over the other; but both are more or less felt together as time goes on. It seems to be a law in physiological pathology that whenever a compound nerve going to the surface is smitten with disease, the effects of that disease are seen in the disturbance of both its main functions ; and this point is one on which I desire now to lay special emphasis. According to the commonly received doctrine, sciatica is a name which denotes a special neuralgia; but in reality it denotes a great deal more; and unless we grasp the fact that sciatica means a lesion of motion as much as a lesion of sensation, we shall understand only half the truth, and our therapentics will be correspondingly lame and unsatisfactory.

This review of what may be called the primary elements of a very common malady will lead us to sympathise with the difficulties in making an early and positive diagnosis. Mr. Jonathan Hutchinson and Dr. Buzzard have undertaken to guide us among the obscurities which surround this important question. The former writer boldly declares that in nineteen cases out of twenty in which the diagnosis of sciatica is suggested there is no affection of the sciatic nerve whatever. They are, according to him, simply cases of arthritic disease of the hip in one or other of its various forms - acute and chronicgout, rheumatoid (or osteo-) artbritis, subacute rheumatism, or chronic senile rheumatism. cases of so-called sciatica, which are not hip-joint rheumatism, some are probably affections of the fascia or periosteum near the hip. ${ }^{2}$ Dr. Buzzard directs attention to the sources of fallacy in the surrounding muscles, and maintains that sciatica may be simulated by $(a)$ myalgia from over-exertion of the flexor muscles at the back of the thigh ; (b) muscular rheumatism in the same muscles, or in those of the leg, from exposure to cold; and (c) a low in. flammatory state of the loose bursal tissue which lies between the muscles, and permits one to slide upon the other. ${ }^{3}$ I think we can hardly wonder that some of the old writers, in a state of puzzled despair, labeled every case of pain about the hip as hip-ache, whenever they could not at once fix its position and identify its cause. In truth, the diagnosis of sciatica is surrounded by pitfalls, some of them deep or so treacherous as to need particular care not to slide in, for when once in we may find it difficult to get out again. I do believe that it is almost safer first to consider every case of so-called sciatica as possibly not sciatica at all certainly much safer than to accept a ready. made diagnosis, and to act upon it without independent observation and inquiry. If our pathological thoughts are so narrow in their range that we rush at once to the idea of sciatica as the most likely solution of any obscure neuralgia of the hip and thigh, we may be right now and then, but much more often we shall be on the wrong track altogether.

A short paper like this cannot be an exhaustive clinical treatise, and here I only try to put up a few sign-posts wherever the way is likely to be missed. Take a patient in any rank of life who has undoubted sciatica, and ask him to point to the exact seat and course of the pain, and the hand usually wanders vaguely over a large surface-area, back and front of the limb, upwards and downwards, pausing here and there along the line of longitude which reaches from the lumbar spine to the extremities of the toes. In only a few cases will the patient point unmistakably to the track of the great sciatic nerve, and say that there, and there only, is the pain. Generally the limb is more or less girdled with pain, reflected down the back of the thigh by the cutaneous twigs of the small sciatic, and along the communicating branches of the obturator and the anterior crural; nor is it uncommon for neuralgic twinges to dart along the pudic nerve to the perineum and the scrotum and to be felt somewhat severely in the knee-joint itself from the tiny branches which go to it from the external popliteal nerve. There is, moreover, usually a lumbar and sacral complication which is apt to be puzzling, arising out of the cutaneous distribution of the lumbar and sacral nerves, and making it almost a proverb that sciatica begins with lumbago, or is associated with it. A unilateral lumbago is very suggestive of sciatica, present or coming Sometimes a sufferer complains most of the pain in the hipjoint, and lays his hand transversely in the groin to tell us where he feels the greatest stress of his malady. Not uncommonly there is much uneasiness among the gluteal muscles, increased by walking, or indeed by any movement no pain at all along the largest part of the sciatic nerve behind the thigh ; but a great deal of tenderness all round the leg, with numbness or tingling in the toes. Now and then there are thermic disturbances in the limb, and surface spots of cold seem to alternate with flushes of heat. Dr. Anstie pointed out long ago that anxsthesia is a common complication of sciatica; showing itself as partial numb ness of skin previous to the first outbreak of the neuralgia and then during the intervals between the attacks. Gradually the anæsthesia is exchanged for a generally diffused hyperoesthesia around the foci of pain ; but stress was laid by Anstie on the fact that tactile sensibility is always diminished. ${ }^{4}$

I will now say a few words on those foei of pain which are characteristic of the more important forms of neuralgia, and which are associated with the name of Valleix, who first described them. In sciatica their interest is great because they unquestionably help to establish a secure diagnosie. Valleix describes seven spots which are permanently and intensely tender, and the slightest passure on which is sufficient to renew the agony of acute pain : $(a)$ a line of points reaching from the lower end of the sacrum up to the crista ilii ; $(b)$ a point opposite the emergence of the great and small sciatic nerves from the pelvis ; $(c)$ a point opposite the

2 Med. Times and Gaz., Jan. 28th, 1882. 3 Practitioner, Feb. 1877. 4 Reynolds's System of Mtdicine, vol. ii , p. 734 
cutaneous emergence of the ascending branches from the small sciatic which run up towards the crista ilii ; $(d)$ several points at the posterior aspect of the thigh ; $(e)$ a fibular point, at the head of the fibula, corresponding to the division of the external popliteal; $(f)$ an external malleolar, behind the outer ankle; $(g)$ an internal malleolar, by the side of the internal ankle. Conceding, as I am obliged to do, that Valleix' doctrines have a tinge of fancy about them, and that it is practically impossible always, or even frequently, to verify all his "tender points," yet the examination of a large number of sciatic patients in the Mineral Water Hospital enables me to speak of the "fibular point" as a tolerable certainty, and easily to be found if inquired for. In two hospital cases there was no pain in the main trunk of the sciatic nerve ; but it began to be felt exactly over the head of the fibula, and extended as a "burning sensation" down the lower part of the leg and over nearly the whole of the foot. In another case the neuralgia of hip and thigh skipped the leg altogether, and made known its existence further on by two exquisitely tender ankles. But it is impossible to delineate here all the aberrant forms of this great neuralgia, which may vary almost from day to day according to the circumstances of weather, clothing, tone of health, and a hundred trivial causes.

And now look for a moment at the motorial symptoms. First, observe how a sufferer may spare the muscles of the affected side because their exercise brings on pain. Secondly, pain and quasi-paralysis are almost always present at the same time, though it may be difficult to distinguish the proportions in which they exist in any given instance. Thirdly, the necessary treatment of any individual case such as prolonged rest and the like, must produce some atrophy of the muscles and weak and awkward movements afterwards. Now these weak and awkward movements in actual execution are often hard to interpret, and sometimes even a riddle to unfold. Note whether the foot be inverted or everted, and whether it strikes the ground with an elastic tread or with a sudden "flop" (a test of the tonicity of the muscles on the front of the leg). Examine the flexor and extensor capabilities of the joints; the presence of hip disease will be determined by the excellent methods of Dr. Macnaughton Jones and Mr. Howard Marsh; do not forget locomotor ataxy and its legion of nerve troubles. Search for enlarged glands, ask about old hernia, blows and falls years ago, and, in the case of a woman, inquire whether sciatica or anything like it ever preceded or followed child bearing.

The rough anatomy of the matter being thus provisionally settled, the medical etiology of the disease must next engage our attention. Gout, rheumatism, and syphilis may affect the neurilemma, the neighbouring fascia and periosteum, and especially the hip-joint itself. Within the range of ordinary probabilities, gradual osteo-arthritis of the hip and the slow rheumatic arthritis of the aged stand first in order, and gentle rotation of the joint should never be neglected The poison of malaria should be thought of in obscure cases, and sometimes pure anæmia has more to do with the disease than probably anything else (as in a young man entrusted to my care last winter by Dr. Richards of Winchester) Nephralgia and a possible calculus must be borne in mind. But whenever the health is obviously failing, and a bilateral pain is prolonged through the lower limbs with increasing intensity and almost ceaseless poignancy, a more definite cause must be sought than a local neuritis or a constitutional dyscrasia. It is here that the most serious mistakes are apt to be made. The functions of the pelvic viscera ought to be thoroughly explored; we should be satisfied that there is no backward displacement of the uterus, weighed down, perhaps, by heavy fibroid tumours; and the rectum must be examined for fæcal accumulation and the possibility of pelvic cancer. Malignant growth from the inner pelvic walls is the undoubted cause of the most agonising sciatic pain, and may be hardly suspected until a tumour is felt through the anterior and lower abdominal wall. Once more : bilateral sciatica (felt most in the thighs), not explicable by any other medico-chirurgical cause, should suggest meningitis or myelitis of the lower part of the spinal cord, as the result of chronic disease or old injury. An almost forgotten concussion of the spine from a fall may set up a long while

5 It is curious to notice how the so-called sciatica, which is a sign of extreme fatigue (from too much walking or standing), is developed in a marked way at one or more of the "tender points," the external fibular being by far the most common. afterwards a sciatica of an obstinate and practically inurable kind. ${ }^{\circ}$

The therapeutics of sciatica cover a wide field. It is not my intention here to travel over ground that is familiar to us all, and to reiterate the stale story of the uncertainty of our prescriptions. We must be masters of many drugs and many methods if we are to be conquerors in that great battle with disorder and disease in which there is often more empiricism than science; but it is better to succeed as empirics than to fail as scientific men! Our quest is for some special remedy which may have the same control over sciatica as quinine has over supra-orbital pain; and failing this, we must take hold of all the rational indications for treatment that we can find. I will suppose now that in a seemingly uncomplicated case of sciatica, caused by $a$ molecular or dynamic disturbance in the nerves themselves, we have given iodide of potassium and quinine in full doses; that we have thoroughly unloaded the bowels by croton oil and colocynth, with perhaps occasional enemata; that turpentine has had its chance in large quantities and small ; that all the most approved narcotics have been administered by the mouth and under the skin (including hypodermic sulphuric ether and hypodermic hot water) $;^{8}$ that every external application has been used which is likely to do good, including dry-cupping and a Spanish-fly blister ; that acupuncture has been tried, and hints have been dropped to the weary and disgusted patient that the surgeon's knife may yet have to be employed in order to carry out " nerve-stretching"-and still the cry is that there is little relief and no prospect of a cure. To prevent recourse to surgical operation, I recommend a consideration of three points, each at its proper season. First, never allow the acute and early stages of sciatica to come and go without a resolute effort to grapple with them. Order complete rest and a posture on the sound side; a strictly milk and vegetable diet; and, whatever else may be done outside and inside, give every three or four hours, for some days, twenty grains of salicylate of soda with a little iodide of potassium and bicarbonate of potash, abundantly diluted with water. Secondly, at the right time remember galvanic electricity, and apply it in the way described by Dr. Wilks in his lectures on Diseases of the Nervous System. Let the current run down the painful limb without moving the rheophores. Place the positive pole over the spine or the hip and the negative pole on the foot, and then let the current run for fifteen minutes or longer. Thirdly, there is the grand resource of bathing in hot water, of which the natural thermal springs of Bath furnish an unlimited supply, with the collateral advantages of comfortable and luxurious baths. We could wish that this resource were not so often long deferred, and that it was recommended with more confidence in all cases in which there is no suspicion of organic mischief elsewhere. For, however deep may be our scepticism about the efficacy of natural mineral waters, there are the obstinate therapeutic facts of our Bath Water Hospital, and the unbiased private experience of every practitioner in our city. It is useless to speculate beyond our knowledge, and our duty at present is to record what we know to be the plain truth about the efficacy of our thermal waters in certain diseases or disorders which have baffled well-devised schemes of drugs and diet. It is certain, however, that bulk, and the alkaline quality of the water have much to do with its therapeutic virtue electric currents may be developed by the rapid passage of nitrogen gas; and while the body is immersed the douche should play on the painful limb, which ought to be stroked and kneaded with a brush or glove. Other manipulations may be done by professional shampooers in the intervals of bathing; but everything of this sort must be carried out with gentle dexterity. The "hip aches" of old days were mostly treated with violent scourgings from the hot water pump, the strokes being counted by the thousand.

A large proportion of young and middle-aged people who

6 In 1880 Dr. W. Miller Ord recommended to my care a gentleman of middle age, in whose case a chronic sciatica on both sides suggested spinal mischief, and a caution on this point was very properly suggested. Very lately a married woman, in the middle rank of lif $\theta$, was sent to me by Dr. Corbet F letcher of Camden-road, Iondon, in whom it seemed nearly certain that a violent blow on the lower spine, inflicted some years ago, had set up a degenerative myelitis, with the sequel of a
torturing sciatica, mainly on the right side.

7 See a paper by Dr. W. Allan Jamieson, in the Edin. Med. Journal, March, 1877.

8 Mr. Merces, resident medical officer at the Mineral Water Hospital, acid in six cases of sciatica with decided but very temporary relief. 
suffer from sciatica are cured by bathing, and recover a good measure of health ; but there is a not unimportant residue in whom this neuralgia (like any other) is a sign of premature bodily decay, and refuses to yield to anything. Almost always we should press the administration of iron and codliver oil, and those fatty foods which promote the integrity of nerve-tissue and of general bodily vigour. Clothing is a matter of personal hygiene which must not be neglected; chamois leather drawers should be worn during the winter and drawers of merino during the three warmest months. If the pain be severe in the leg, and there be signs of vasomotor disturbance, such as erysipelas and cedema, I advise a bandage to be worn during the daytime. The even pressure of a bandage controls muscular spasms, and helps a weak circulation. The allies and counterfeits of sciatica, as lumbago and rheumatic myalgia in any part of the lower limb, are generally much alleviated by the proper and persevering use of the Bath thermal waters.

\section{A NEW SPONGE.}

BY SAMPSON GAMGEE, F.R.S.E., CONSULTING SURGEON TO THE QUEEN'S HOSPITAL, BIRMING HAM.

IN recently addressing the Society of Surgery in Paris on the uses of the new sponge, I made some observations, for $n$ abstract of which I claim the privilege of publicity in the columns of THE LANCET, in continuation of the first published notice on the subject. ${ }^{1}$

Conceding that ordinary sponges may, by extraordinary precantions in boiling and antiseptic cleansing, be so used as to prevent infection, the fact remains that they are such a fertile source of mischief, as to be no longer employed by many of the most skilled and conscientious operators. Whereas even the best new natural sponges require much preparation before use, and only absorb after being moistened, the sponges made according to my plan by Messrs. Burroughs and Wellcome are always ready, and absolutely pure. The antiseptic, preserved intact within the capsule, is set free by a light squeeze just when required, and it then diffuses itself instantly throughout the sponge tissue. How quickly and powerfully this absorbs may be demonstrated by a very simple experiment. On a tumbler, brimful of water, lightly hold one of the sponges just in contact with the liquid; as this perceptibly falls in the vessel, gradually press the sponge down into it. By a little care, it is easy to fill the tumbler with the sponge, without spilling a drop of water. The sponge absorbs from sixteen to eighteen times its own weight of liquid. If the sponge capsule have been cracked before the sponge is im. mersed, the liquid emits the odour of the antiseptic employed; and I have now before me a tumbler containing one of the sponges and water in which it was immersed three weeks ago. The odour of the eucalyptus oil, which filled the capsule, is still most distinctly perceptible. As any antiseptic may be enclosed in the capsule, sponges may be used to make their own antiseptic and cleansing lotion, according to the indications of the case and the surgeon's views. For additional guarantee of absolute asepticity, the sponge materials may be prepared with borax, salicylic acid, or bichloride of mercury, and the sponges may be sterilised by high temperature, and enclosure in sealed vessels. In nursing patients affected with infectious disease, it appears reasonable to expect that the great sanitary principle of isolation may be promoted by burning the sponges, after using them for collecting discharges and cleansing the person. In child-bed, large sponge pads containing two or more antiseptic capsules appear well calculated to ensure comfort and safety; but as this is a department of practice in which $I$ have no personal experience, the hint is only tentatively offered.

I have already acknowledged my indebtedness to $\mathrm{Sir}$ Spencer Wells; and his anticipations are borne out by Dr. Robert Barnes and Dr. Thomas Savage. The latter has favoured me with a note suggesting that the sponges may be useful for $(a)$ plugging the vagina in some cases of hæmorrhage - e.g., threatened abortion; (b) retaining laminaria tents in situ in the uterus; and $(c)$ in some cases of uterine deviation, as a tampon.

My friend and colleague, Mr. Priestley Smith, thinks that these sponges may be of special value in ophthalmic prac- tice, a suggestion entirely in accord with my own experience of the comfort and safety attending their use in operative surgery generally.

In principle, the new sponge and wound pad, with its antiseptic nucleus in absorbent materials, is as elastic and adaptable, as are the physical properties of its constituents. In the endeavour to discover a via media between theoretically conflicting systems, it is to be hoped that a practicable com. promise has been effected between the antiseptic and dry methods of wound treatment, - that improved means have been devised for surface drainage and physiological pressure,and that, by technical simplification, the practice of scientific methods in every day surgery, and in the sick room generally, has been made easier and safer.

Birmingham.

\section{A CASE OF RUPTURE OF THE UTERUS:}

By J. MACKENZIE BOOTH, M.B., C.M., PHYSICIAN TO THE ABERDEEN GENERAL DISPENSARY.

ON account of its infrequency as well as from the special difficulties encountered in the management of the following case of rupture of the uterus, I think it worthy of record.

On the morning of the 15th of January last I was sent for by one of the students working in my district to assist him in a dispensary confinement in East North-street. The patient was a woman of middle stature but of huge bulk, weighing (the neighbours said, and it appeared likely enough), about eighteen stone, and was now being confined for the third time. The first confinement had been normal, the second severe and protracted. The patient had expected to be ill some time ago, and had not felt any movement for several days. Mr. Hutcheon, the gentleman in charge, told me he had been with the woman for four hours, that the labour pains, which at first had been long and strong, had ceased, and that as there seemed to be no progress in the labour he had sent for me. I found the os well open and the vertex presenting normally, but the head very high up above the pelvic brim. Stimulation of the os only excited very feeble uterine contactions. I ordered a teaspoonful of liquid extract of ergot, and a smaller dose in half an hour's time was to be given if I did not return. I left, and having finished part of my work, returned in less than an hour, this time taking a pair of forceps with me. Matters were still in statu quo, and neither was the administration of ergot nor stimulation of the fundus or os of any avail in in. ducing uterine action. The patient complained of sharp but not excessive pain over the lower part of the abdomen, and was evidently much exhausted. I then attempted to apply the forceps, but owing to the height of the presentation utterly failed to do so. I repeatedly withdrew and reintro. duced the blades, trying to get them applied, but finding it of no avail $I$ determined to turn and deliver by the breech. This was not so easily done, as from the thickness of the abdominal wall manipulation was well nigh impossible, and even when the hand was passed up into the uterine cavity the legs were so far up that it was difficult to get hold of a foot or knee. After some delay I hooked the left knee with my forefinger, and brought it down into the vagina; and when the foot was pulled externally to the labia, I found the skin coming off in my band, and the tissues soft and flabby, the child having evidently been dead for some time. On this account less force was used in attempting extraction than would other wise have been done. By degrees and with difficultly, from the resistance of the soft parts and the absence of uterine contraction, the other leg, trunk, and arms were brought down, and then I could feel that the spinal column had given way near the sixth cervical vertebra, the skin being intact and the neck greatly elongated. This, of course, rendered the utmost eare necessary in making traction in order to deliver the head; and it was soon obvious that it would be impossible, in the absence of uterine con. traction, to bring down the head without risking the con. tinuity of the neck. The forceps were accordingly again had recourse to, but so high was the head that I repeatedly failed to get them applied. In this dilemma I sent for our late senior colleague, Dr. Hall, who happened to be engaged at the time, but promised to come shortly to my assistance. Thinking it would give more space for using the forceps, $I$ cut across the trunk of the child from the right shoulder to

1 Read before the Aberdeen Medico-Chirurgical Society on March 6th. 